\title{
SCREENING STUDIES OF ANTIMICROBIAL EFFICACY OF ANTISEPTICS AS ONE OF THE WAYS TO PREVENT NOSOCOMIAL INFECTIONS IN DENTISTRY
}

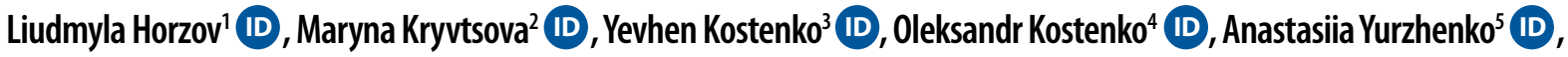 \\ Goderdzi Nakashydze ${ }^{5}$, Oleksandr Bilynskyi' (ID)
}

'Department of Therapeutic Dentistry, Uzhhorod National University, Uzhhorod, Ukraine

${ }^{2}$ Department of Genetics, Plant Physiology, and Microbiology, Department of Fundamental Medicine Science, Uzhhorod National University, Uzhhorod, Ukraine

${ }^{3}$ Department of Orthopedic Dentistry, Uzhhorod National University, Uzhhorod, Ukraine

${ }^{4}$ Department of Fundamental Medicine Science, Uzhhorod National University, Uzhhorod, Ukraine

${ }^{5}$ Department of Dentistry, postgraduate education with a course of therapeutic and orthopedic dentistry, Uzhhorod National University, Uzhhorod, Ukraine

\begin{abstract}
INTRODUCTION: Over the last decades, the problem of formation and circulation of micro-organisms with resistance to antimicrobials has been steadily increasing. Hospital-acquired infections (HAI) are one of the most pressing problems in medicine, urgency of which is associated with high rates of morbidity, mortality, and significant socio-economic losses.

ОвјестіVEs: The aim of the study was to investigate antimicrobial activity of commercial disinfectants on typical and clinical isolates of bacteria of genus Staphylococcus.

MATERIAL AND METHODS: Clinical base for isolation of bacteria was the University Dental Clinic of Uzhhorod National University, and evaluation of antimicrobial activity of disinfectants was conducted in microbiological laboratory of the Department of Genetics, Plant Physiology and Microbiology of Uzhhorod National University, Ukraine. Sensitivity of micro-organisms to disinfectants was determined using standard method of diffusion into agar (well diameter, $8 \mathrm{~mm}$ ).

Results: Previous studies have shown that in vitro experiments, the highest anti-staphylococcal effect was observed using Ecobriz antiseptic, AHD 2000, and Lysoformin 3000. It should be noted that sensitivity of coagulasenegative staphylococci was statistically significantly higher than that of coagulase-positive. Thus, the growth retardation zone under the action of AHD 2000 on clinical strain of Staphylococcus aureus was $19.0 \pm 0.30 \mathrm{~mm}$ and on S. haemolyticus it was $23.9 \pm 1.0 \mathrm{~mm}$. This trend was characteristic for other antiseptics. The lowest antimicrobial activity was detected by using Chlorhexidine. Antimicrobial action of ethanol at applied dose was not observed. The highest activity among staphylococci was detected using antiseptics on S. hominis isolates.

ConcLusions: Experiments established antimicrobial activity of all antiseptics except Dezoderm and Etasept. The highest level of activity against Gram-positive, Gram-negative bacteria, and microscopic fungi was found in Bacylol. High levels of antimicrobial activity were detected using AHD 2000, Lysoformin 3000, Ecobriz antiseptic, and Famidez, with higher activity of antiseptics against bacteria of genus Staphylococcus.
\end{abstract}

KEY WORDS: antiseptics, disinfection, nosocomial infection.

J Stoma 2021; 74, 4: 243-248

DOI: https://doi.org/10.5114/jos.2021.111287

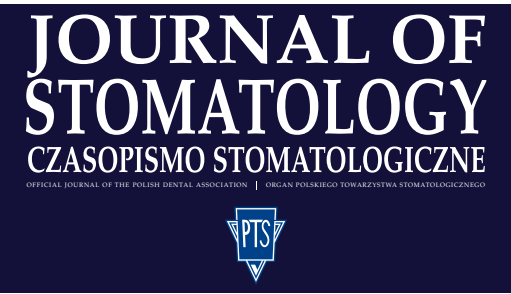

ADDRESS FOR CORRESPONDENCE: Liudmyla Horzov,

Department of Therapeutic Dentistry, Uzhhorod National University,

16a Universytetska St., 88000 Uzhhorod, Ukraine, phone: + 380507626129 ,

e-mail: liudmyla.horzov@uzhnu.edu.ua

ReCEIVED: 29.03.2021 • ACCEPTED: 03.10.2021 • PUBLISHED: 31.11.2021 


\section{INTRODUCTION}

Over the last decades, the problem of formation and circulation of micro-organisms with resistance to antimicrobials has been steadily increasing. Hospitalacquired infections (HAI) are one of the most pressing problems in medicine, urgency of which is associated with high rates of morbidity, mortality, and significant socio-economic losses [1]. For the treatment and prophylactic dental profile institutions, the problem of HAI is most urgent since microbiota associations with the oral cavity include conditionally pathogenic micro-organisms. In recent decades, scientists have found a decrease in the effectiveness of antiseptics [2]. Resistance of micro-organisms to antimicrobial drugs is associated with ability of a micro-organism to acquire resistance through horizontal transfer of genes (plasmids, transposons), and with biofilm-forming properties of hospital strains. Moreover, a study by Gajadhar et al. showed that disinfectants themselves can be contaminated with micro-organisms [3]. This further indicates a high-rate of growth of antimicrobial resistance.

To date, there is significant number of antiseptic drugs on the market [4]. Modern antiseptics must be effective and non-toxic. In terms of COVID-19 pandemic and quarantine measures with permanent use of antiseptics, their effectiveness may decrease dramatically.

In dental clinic, the source of HAI is the patient or the carrier, and factors of transmission include blood, saliva, pus, not disinfected dental equipment and medical instruments, towels, sinks, door handles, chairs, etc. In this regard, not only the patient but also medical staff are at risk of infection [5]. Under these conditions, there is a growing need for monitoring studies evaluating the effectiveness of antimicrobial agents to develop effective approaches in using antiseptics and disinfectants.

\section{OBJECTIVES}

The aim of the study was to investigate the antimicrobial activity of commercially available disinfectants on typical and clinical isolates of bacteria of genus Staphylococcus.

\section{MATERIAL AND METHODS}

The clinical base for isolation of bacteria was the University Dental Clinic of Uzhhorod National University (UzhNU). Evaluation of antimicrobial activity of disinfectants was conducted in microbiological laboratory of the Department of Genetics, Plant Physiology, and Microbiology of UzhNU, Ukraine. Sensitivity of microorganisms to disinfectants was determined with standard method of diffusion into agar (well diameter, $8 \mathrm{~mm}$ ) $[6,7]$. Commercially available antiseptics were used in the study, composition of which is given in Table 1.

As test cultures, bacteria of genus Staphylococcus, Staphylococcus aureus ATCC 25923, clinical isolates of $S$. aureus bacteria were used, including methicillin-resistant, S. epidermidis, S. haemolyticus, S. hominis isolated from the mouth of people with inflammatory periodontal disease. As test cultures, bacteria and yeasts from American type culture collection were applied, including Staphylococcus aureus ATCC 25923, Escherichia coli ATCC 25922, Streptococcus pyogenes ATCC 19615, and Candida albicans ATCC 885-653. Moreover, samples with clinical strains of bacteria and yeasts (Staphylococcus aureus bacteria, such as methicillin-resistant $S$. epidermidis, S. haemolyticus, S. hominis, Escherichia coli, Streptococcus pyogenes, and Candida albicans), isolated from hands of dentists and oral cavities of patients suffering from inflammatory diseases of periodontium were used.

Inoculum of bacteria or microscopic fungi with $100 \mu \mathrm{l}$ in saline containing $5 \times 10^{8} \mathrm{CFU} / \mathrm{ml}(0.5 \mathrm{Mc}$ -

TABLE 1. Antiseptics used in the study

\begin{tabular}{|c|c|c|}
\hline Disinfectants & Manufacturer & Active substance, $\%$ \\
\hline AHD 2000 & Blanidas, Ukraine & $\begin{array}{l}\mathrm{N} \text {-propanol, } 40 \% \text {; isopropanol, } 35 \% \text {; } \\
\text { alkyldimethylbenzylammonium chloride, } 0.15 \% \text {; } \\
\text { aromatic substances, water }\end{array}$ \\
\hline Lyzoformin 3000 & Lyzoform, Dr. Hans Rosemann GmbH, Germany & Glutaraldehyde, $9.5 \%$; glyoxal, $7.5 \%$; didecyldimethylammonium chloride, $9.6 \%$ \\
\hline Hospisept gel & Blanidas, Ukraine & Sodium salt of dichloroisocyanuric acid, $85.5 \%$ \\
\hline Chlorhexidine digluconate & Monpharm, Ukraine & Chlorhexidine bigluconate, $20 \%$ \\
\hline Ecobriz & World of Disinfection, Russia & $\begin{array}{l}\text { Alkyldimethylbenzylammonium, } 0.15 \% \text {; chloride + didecyldimethylammonium } \\
\text { chloride; isopropyl alcohol (propanol-2), } 60 \%\end{array}$ \\
\hline Famidez & DezoMark ${ }^{\oplus}$,Ukraine & $\begin{array}{l}\text { Propanol, } 60.00-66.62 \% ; 1.3 \text {-butanediol, } 0.104-0.126 \% \text {; moisturizing } \\
\text { and softening skin additives, water (up to } 100.0 \text { ) }\end{array}$ \\
\hline Bacyllol & BODE Chemie GmbH, Ukraine & 1-propanol, 45.0\%; 2-propanol, 25.0\%; ethanol, 4.7\% \\
\hline Desoderm & DezoMark ${ }^{\oplus}$,Ukraine & Isopropyl alcohol, 60.0-66.5\%; 1.3-dibutyl alcohol, 0.104-0.126\% \\
\hline Etasept & Blanidas, Ukraine & Ethyl alcohol, $9.5-10.5 \%$ \\
\hline
\end{tabular}


Farland standard) were sown on the surface of MullerHinton agar. Wells were formed in the agar with a diameter of $6 \mathrm{~mm}$, in which test drugs were introduced with $200 \mu \mathrm{l}$. They were incubated at $37 \pm 2^{\circ} \mathrm{C}$ for 24 hours. Diameter of the growth retardation zones was measured in $\mathrm{mm}$, including diameter of the well. Each measurement of antimicrobial activity was performed three times. Antibacterial properties were evaluated according to the following criteria: $10 \mathrm{~mm}$ - no growth retardation zone, indicating that micro-organisms are not sensitive to the specimen introduced into the well; from 10-15 mm, showing weak level of sensitivity; 15-25 mm - sample sensitive; more than $25 \mathrm{~mm}$ - high sensitivity.

Assessment of effectiveness of antiseptics was also performed by examining microbiota of the hands of dentists before and after using antiseptic. Application on the hands was performed by applying a $3 \mathrm{ml}$ of antiseptic on dry skin of the hands, followed by rubbing it into the skin for at least 30 seconds.

Hands washing was done using a sterile cotton swab pre-soaked in sterile saline before and after treatment with an appropriate antiseptic. The study involved 48 dentists, and samples were sown on differential diagnostic media, including sabouraud dextrose agar (HiMedia) for the cultivation of genus Candida microscopic fungi on hemolytic microflora, such as bacteria of Streptococcus and Neisseria - on blood agar, Enterobacteriaceae - Endo medium, and bacteria of genus Staphylococcus were cultured on mannitol salt agar (Biolife Italiana; Italy), bacteria of genus Enterococcus agar (Biolife Italiana; Italy). Identification of micro-organisms was performed using biochemical test systems, i.e., ENTERO-test, STREPTO-test, STAPHYLO-test (Erba Lachema; Czech Republic).

Each antimicrobial assay was performed at least three times. Obtained data were expressed as mean \pm standard deviation $(\times \pm S D)$ of the three measurements. Tukey's test was applied for comparisons of means, and differences were considered significant at $p<0.05$.

\section{RESULTS}

Previous studies have demonstrated that in vitro experiments, the highest anti-staphylococcal effect was observed using Ecobriz antiseptic, AHD 2000, and Lysoformin 3000 . It should be noted that the sensitivity of coagulase-negative staphylococci was statistically significantly higher than that of coagulase-positive (Table 2).

Therefore, the growth retardation zone while using AHD 2000 on clinical strain of Staphylococcus aureus was $19.0 \pm 0.30 \mathrm{~mm}$, and on S. haemolyticus it was 23.9 $\pm 1.0 \mathrm{~mm}$. This trend was characteristic for other antiseptics. The lowest antimicrobial activity was detected with the use of chlorhexidine. Antimicrobial action of ethanol at applied dose was not observed. The highest activity among staphylococci was detected using antiseptics on $S$. hominis isolates.
A total of 8,104 isolates of bacteria of Staphylococcus was isolated and identified, including S. epidermidis, S. aureus, S. saprophyticus, S. haemolyticus, S. hominis. $S$. aureus - 26 isolates, all of them lecithinase-positive. S. epidermidis (8,011 isolates) was most often isolated, and $66 \%$ of S. epidermidis isolates were characterized by hemolytic activity.

Bacteria of Enterobacteriaceae family were isolated in one case, represented by one species of Enterobacter cloacae. No microscopic fungi were detected in any of the samples. Saprophytic micro-organisms represented bacteria of genus Micrococcus spp., Bacillus spp., and Actinomyces spp.

In vitro experiments established antimicrobial activity of all drugs, except for Dezoderm and Etasept. The highest level of activity against Gram-positive, Gramnegative bacteria, and microscopic fungi was found using Bacylol. High levels of antimicrobial activity against isolates were detected using AHD 2000, Lysoformin 3000, Ecobriz, and Ramidez antiseptics, with high activity of disinfectants detected against Staphylococcus bacteria (Table 2). During application of disinfectants on doctor's hands, the activity of antiseptics were established, except for Etasept (Table 3).

\section{DISCUSSION}

Problem of circulation of antibiotic-resistant pathogens of nosocomial infections is relevant worldwide. According to Weiner et al., 4,515 hospitals reported that at least one case of HAI occurring between 2011 and 2014, and 408,151 pathogenic micro-organisms were registered from 365,490 infected patients. Fifteen groups of pathogens accounted for $87 \%$ of reported pathogens, out of which, the most common were Escherichia coli (15\%), Staphylococcus aureus (12\%), Klebsiella species (8\%), and coagulase-negative staphylococci (8\%). In general, the proportion of isolates with common resistance phenotypes was higher among devices associated with HAI compared to infections at surgical site. Although the percentage of resistance for most phenotypes was similar to previous reports, there was an increase in the percentage of resistance among Escherichia coli pathogens, especially those associated with fluoroquinolone resistance. The authors emphasized the need for constant and careful monitoring of these data within HAI types [8].

Our results indicated that the hands are a significant source of opportunistic pathogens. At the same time, the constant use of antiseptics promotes the development of resistance of micro-organisms to antimicrobial drugs. Our research has shown a predominant contamination of hands with different species of Staphylococcus because the culture test was used in both museum and clinical strains of different species of this genus.

There are various methods for determining antimicrobial activity of substances, including disco-diffusion, 


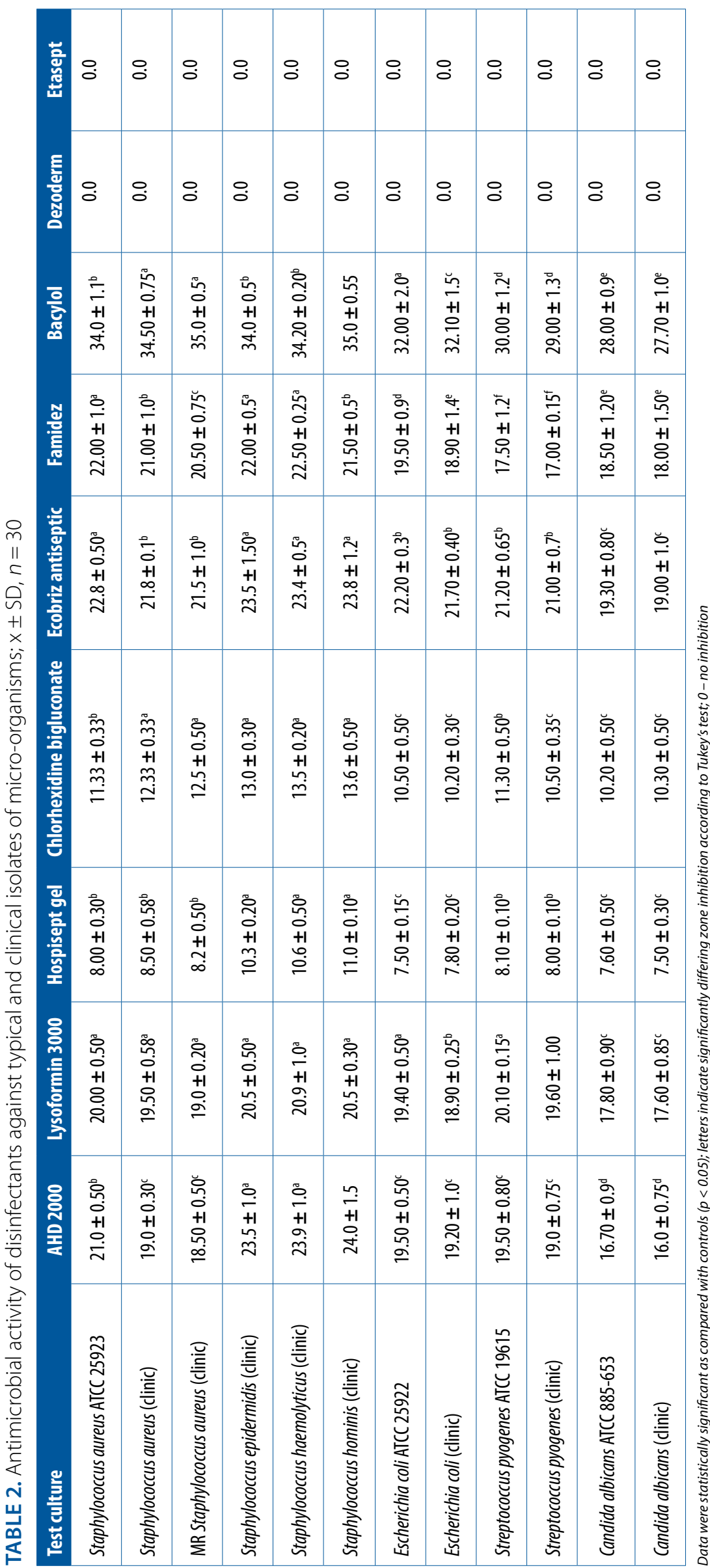


TABLE 3. Microbial contamination of dentists' hands before and after antiseptic treatment; $\times \pm S D, n=48$, microbial count

\begin{tabular}{|c|c|c|c|c|c|}
\hline Antiseptics & $\begin{array}{l}\text { Before/after } \\
\text { processing }\end{array}$ & $\begin{array}{l}\text { Total microbial } \\
\text { count }\end{array}$ & $\begin{array}{l}\text { Total number of hemolytic } \\
\text { micro-organisms }\end{array}$ & Bacteria of genus Staphylococcus & $\begin{array}{l}\text { Coli-form } \\
\text { bacteria }\end{array}$ \\
\hline \multirow[t]{2}{*}{ AHD 2000} & Before & $56.0 \pm 1.0$ & 0.0 & $\begin{array}{c}9.0 \pm 0.50, \text { Staphylococcus aureus } \\
19.0 \pm 1.0, \text { Staphylococcus epidermidis } \\
24.0 \pm 2.0, \text { Staphylococcus saprophyticus } \\
4.0 \pm 0.5, \text { Micrococcus luteus }\end{array}$ & 0.0 \\
\hline & After & $1.0 \pm 0.5$ & 0.0 & 0.0 & 0.0 \\
\hline \multirow[t]{2}{*}{ Lysoformin 3000} & Before & $39.0 \pm 2.0$ & 0.0 & $\begin{array}{c}9.0 \pm 0.5, \text { Micrococcus luteus } \\
20.0 \pm 0.7 \text {, Staphylococcus epidermidis } \\
10.0 \pm 1.0 \text {, Staphylococcus saprophyticus }\end{array}$ & 0.0 \\
\hline & After & 0.0 & 0.0 & 0.0 & 0.0 \\
\hline \multirow[t]{2}{*}{ Hospisept gel } & Before & $80.0 \pm 2.5$ & $6.0 \pm 1.0$ & $\begin{array}{c}13.0 \pm 2.0, \text { Staphylococcus aureus } \\
51.0 \pm 1.5, \text { Staphylococcus epidermidis }\end{array}$ & 0.0 \\
\hline & After & 0.0 & 0.0 & 0.0 & 0.0 \\
\hline \multirow[t]{2}{*}{$\begin{array}{l}\text { Chlorhexidine } \\
\text { bigluconate }\end{array}$} & Before & $68.00 \pm 0.1$ & & $\begin{array}{c}27.0 \pm 0.25, \text { Staphylococcus aureus } \\
25.0 \pm 2.0, \text { Staphylococcus epidermidis } \\
16.0 \pm 0.25, \text { Bacillus spp. }\end{array}$ & 0.0 \\
\hline & After & 0.0 & 0.0 & 0.0 & 0.0 \\
\hline \multirow[t]{2}{*}{ Ecobriz } & Before & $2.5 .0 \pm 1.5 \times 10^{2}$ & 0.0 & $\begin{array}{c}20.0 \pm 0.50, \text { Staphylococcus aureus } \\
5.0 \pm 1.0, \text { Staphylococcus saprophyticus }\end{array}$ & 0.0 \\
\hline & After & 0.0 & 0.0 & 0.0 & 0.0 \\
\hline \multirow[t]{2}{*}{ Famidez } & Before & $30.0 \pm 1.5$ & 0.0 & $\begin{array}{c}4.0 \pm 1.0, \text { Staphylococcus aureus } \\
21.0 \pm 0.5, \text { Staphylococcus epidermidis } \\
5.0 \pm 1.0, \text { Staphylococcus hominis }\end{array}$ & 0.0 \\
\hline & After & 0.0 & 0.0 & 0.0 & 0.0 \\
\hline \multirow[t]{2}{*}{ Bacylol } & Before & $57.0 \pm 2.0 \times 10^{2}$ & 0.0 & $\begin{array}{c}49.0 \pm 4.0 \times 10^{2}, \text { Staphylococcus } \\
\text { epidermidis } \\
2.0 \pm 2.5, \text { Staphylococcus saprophyticus } \\
5.0 \pm 1.5, \text { Micrococcus luteus }\end{array}$ & 0.0 \\
\hline & After & 0.0 & 0.0 & 0.0 & 0.0 \\
\hline \multirow[t]{2}{*}{ Dezoderm } & Before & $3.0 \pm 1.5 \times 10^{3}$ & 0.0 & $\begin{array}{c}3.0 \pm 0.5 \times 10^{3}, \text { Staphylococcus } \\
\text { epidermidis }\end{array}$ & 0.0 \\
\hline & After & 0.0 & 0.0 & 0.0 & 0.0 \\
\hline \multirow[t]{2}{*}{ Etasept } & Before & $152.0 \pm 3.5$ & 0.0 & $\begin{array}{l}8.0 \pm 0.5, \text { Staphylococcus haemolyticus } \\
24.0 \pm 3.0 \text {, Staphylococcus saprophyticus }\end{array}$ & $120.0 \pm 3.0$ \\
\hline & After & $\begin{array}{r}70.0 \pm 2.0 \\
\text { Bacillus spp. }\end{array}$ & $1.0 \pm 0.50$ & 0.0 & $50.0 \pm 2.0$ \\
\hline
\end{tabular}

a method of determining minimum inhibitory concentrations, and method of diffusion into agar [6]. The chosen method of diffusion into agar allowed to objectively assess bactericidal activity of an antiseptic by areas of growth retardation. This method used was fast and not expensive.

Analyzing data from Lin et al., their meta-regression assessment suggested that pooled rate of $S$. aureus contamination was lower in studies conducted in developed countries (OR $=0.664 ; 95 \%$ CI: $0.509-0.867 ; p=0.004)$. $S$. aureus and MRSA contamination statuses of hightouch items are worrisome, and should be considered even more. Developing country status is a risk factor for
S. aureus contamination [9]. Scientists from Oman reported that antibiotic resistance to erythromycin (48\%) and clindamycin (29\%) was relatively high, and $9.3 \%$ of HA-MRSA isolates were vancomycin-resistant (nasal carriage, 6.6\%) [10].

El Sayed in a study confirmed association between the presence of antiseptic resistance genes and resistance to different antibiotics, which may be attributed to the presence of both groups of genes on the same plasmid or to selection of resistant strains [11].

Our work showed a high level of circulation of antibiotic-resistant isolates of micro-organisms in patients 
with generalized periodontitis [12]. Prospects of developing antiseptics based on natural ingredients have also been established [13]. Htun reported that antiseptic exposures were associated with carriage of qac genes, whereas chlorhexidine exposure was related to reduced chlorhexidine susceptibility, requiring continued surveillance for the emergence of resistance [14].

Combination of antiseptics, such as EDTA (ethylenediaminetetraacetic acid) and proteases at low concentrations, revealed a synergistic effect leading to total eradication of dense biofilms of both Pseudomonas aeruginosa and Staphylococcus aureus [15].

Our results and data from other authors indicate the need for continuous monitoring of sensitivity of microorganisms to antiseptics in a particular clinic in order to use effective safe antiseptics as well as to prevent infection of patients and physicians.

\section{CONCLUSIONS}

Experiments have shown that the surface of doctors' hands before antiseptic treatment, is mostly contaminated with various species of Staphylococcus bacteria, which can be a source of infection for patients. Experiments established antimicrobial activity of all drugs, except for Dezoderm and Etasept. The highest level of activity against Gram-positive, Gram-negative bacteria, and microscopic fungi was found using Bacylol, with higher activity of antiseptics against bacteria of genus Staphylococcus than representatives of Gram-negative bacteria. The obtained results substantiate the prospects of studying the circulation of micro-organisms within clinics. The study of hands' microbiota, personal use of doctors, and microorganisms circulating in dental offices, would examine the effectiveness of disinfectants and develop local protocols for disinfection within a particular clinic.

\section{CONFLICTS OF INTEREST}

The authors declare no potential conflicts of interest with respect to the research, authorship, and/or publication of this article.

\section{References}

1. WHO. The burden of health care-associated infection worldwide (2016) [Online]. Available from: http://www.who.int/gpsc/country_work/burden_hcai/en/ (Accessed: 10.08.2016).

2. Russell AD. Bacterial resistance to disinfectants: present knowledge and future problems. J Hosp Infect 1999; 43 Suppl: S57-68. doi: 10.1016/s0195-6701(99)90066-x.

3. Gajadhar T, Lara A, Sealy P, Adesiyun AA. Microbial contamination of disinfectants and antiseptics in four major hospitals in Trinidad. Rev Panam Salud Publica 2003; 14: 193-200.

4. Jackson MM. Topical antiseptics in healthcare. Clin Lab Sci Summer 2005; 18: 160-169.
5. Khan HA, Baig FK, Mehboob R. Nosocomial infections: epidemiology, prevention, control and surveillance. Asian Pac J Trop Biomed 2017; 7: 478-482.

6. Ríos JL, Recio MC. Medicinal plants and antimicrobial activity. J Ethnopharmacol 2005; 100: 80-84.

7. Balouiri M, Sadiki M, Ibnsouda SK. Methods for in vitro evaluating antimicrobial activity: a review. J Pharm Anal 2016; 6: 71-79.

8. Weiner LM, Webb AK, Limbago B, et al. Antimicrobial-resistant pathogens associated with healthcare-associated infections: summary of data reported to the National Healthcare Safety Network at the Centers for Disease Control and Prevention, 2011-2014. Infect Control Hosp Epidemiol 2016; 37: 1288-1301.

9. Lin D, Ou Q, Lin J, Peng Y, Yao Z. A meta-analysis of the rates of Staphylococcus aureus and methicillin-resistant $S$ aureus contamination on the surfaces of environmental objects that health care workers frequently touch. Am J Infect Control 2017; 45: 421-429.

10. Pathare NA, Asogan H, Tejani S, et al. Prevalence of methicillin resistant Staphylococcus aureus [MRSA] colonization or carriage among health-care workers. J Infect Public Health 2016; 9: 571-576.

11. El Sayed Zaki M, Bastawy S, Montasser K. Molecular study of resistance of Staphylococcus aureus to antiseptic quaternary ammonium compounds. J Glob Antimicrob Resist 2019; 17: 94-97.

12. Kryvtsova MV, Kostenko YeYa. Dominant microbial associations of the oral cavity in the conditions of generalized periodontitis and features of there sensitivity to antibacterial drugs. Studia Biologica 2020; 14: 51-62.

13. Kryvtsova MV, Kostenko YY, Salamon I. Compositions of essential oils with antimicrobial properties against isolates from oral cavities of patients with inflammatory diseases of parodentium. Regulatory Mechanisms in Biosystems 2018; 9: 491-494.

14. Htun HL, Hon PY, Holden MTG, Ang B, Chow A. Chlorhexidine and octenidine use, carriage of qac genes, and reduced antiseptic susceptibility in methicillin-resistant Staphylococcus aureus isolates from a healthcare network. Clin Microbiol Infect 2019; 25: 1154.e1-1154.e7.

15. Lefebvre E, Vighetto C, Di Martino P, Larreta Garde V, Seyer D. Synergistic antibiofilm efficacy of various commercial antiseptics, enzymes and EDTA: a study of Pseudomonas aeruginosa and Staphylococcus aureus biofilms. Int J Antimicrob Agents 2016; 48: 181-188. 